OPEN ACCESS

Edited by:

Amy Lovett-Racke,

The Ohio State University,

United States

Reviewed by:

Michael Dietrich,

University Hospital of Düsseldorf,

Germany

Ermelinda De Meo,

San Raffaele Hospital (IRCCS),

Italy

*Correspondence:

Christina Alves Peixoto

peixoto.christina@gmail.com

Eduardo Duarte-Silva

eduardo.pduartesilva@gmail.com

Specialty section:

This article was submitted to

Multiple Sclerosis and

Neuroimmunology,

a section of the journal

Frontiers in Immunology

Received: 23 February 2021

Accepted: 19 April 2021

Published: 13 May 2021

Citation:

Duarte-Silva E, Meiry da Rocha Araújo S, Oliveira WH, Lós DB, Bonfanti AP,

Peron $G$, de Lima Thomaz $L$,

Verinaud $L$ and Peixoto CA (2021)

Sildenafil Alleviates Murine

Experimental Autoimmune

Encephalomyelitis by Triggering

Autophagy in the Spinal Cord.

Front. Immunol. 12:671511.

doi: 10.3389/fimmu.2021.671511

\section{Sildenafil Alleviates Murine Experimental Autoimmune Encephalomyelitis by Triggering Autophagy in the Spinal Cord}

\author{
Eduardo Duarte-Silva $a^{1,2,3^{*}}$, Shyrlene Meiry da Rocha Araújo ${ }^{1,4}$, Wilma Helena Oliveira ${ }^{1,4}$, \\ Deniele Bezerra Lós ${ }^{5}$, Amanda Pires Bonfanti ${ }^{6}$, Gabriela Peron ${ }^{6}$, Livia de Lima Thomaz ${ }^{6}$ \\ Liana Verinaud ${ }^{6}$ and Christina Alves Peixoto ${ }^{1,7^{*}}$
}

\footnotetext{
${ }^{1}$ Laboratory of Ultrastructure, Aggeu Magalhães Institute (IAM), Recife, Brazil, 2 Postgraduate Program in Biosciences and Biotechnology for Health (PPGBBS), Oswaldo Cruz Foundation (FIOCRUZ-PE)/Aggeu Magalhães Institute (IAM), Recife, Brazil, ${ }^{3}$ Network of Immunity in Infection, Malignancy and Autoimmunity (NIIMA), Universal Scientific Education and Research Network (USERN), Recife, Brazil, ${ }^{4}$ Postgraduate Program in Biological Sciences/Center of Biosciences, Federal University of Pernambuco (UFPE), Recife, Brazil, ${ }^{5}$ Postgraduate Program in Biotechnology/Northeast Network in Biotechnology (RENORBIO), Federal University of Pernambuco (UFPE), Recife, Brazil, ${ }^{6}$ Department of Structural and Functional Biology, University of Campinas (UNICAMP), Campinas, Brazil, 7 National Institute of Science and Technology on Neuroimmunomodulation (INCT-NIM), Oswaldo Cruz Institute, Oswaldo Cruz Foundation, Rio de Janeiro, Brazil
}

Multiple Sclerosis (MS) is a neuroinflammatory and chronic Central Nervous System (CNS) disease that affects millions of people worldwide. The search for more promising drugs for the treatment of MS has led to studies on Sildenafil, a phosphodiesterase type 5 Inhibitor (PDE5I) that has been shown to possess neuroprotective effects in the Experimental Autoimmune Encephalomyelitis (EAE), an animal model of MS. We have previously shown that Sildenafil improves the clinical score of EAE mice via modulation of apoptotic pathways, but other signaling pathways were not previously covered. Therefore, the aim of the present study was to further investigate the effects of Sildenafil treatment on autophagy and nitrosative stress signaling pathways in EAE. 24 female C57BL/6 mice were divided into the following groups: $(A)$ Control - received only water; (B) EAE - EAE untreated mice; (C) SILD - EAE mice treated with $25 \mathrm{mg} / \mathrm{kg}$ of Sildenafil s.c. The results showed that EAE mice presented a pro-nitrosative profile characterized by high tissue nitrite levels, lowered levels of p-eNOS and high levels of iNOS. Furthermore, decreased levels of LC3, beclin-1 and ATG5, suggests impaired autophagy, and decreased levels of AMPK in the spinal cord were also detected in EAE mice. Surprisingly, treatment with Sildenafil inhibited nitrosative stress and augmented the levels of LC3, beclin-1, ATG5, pCREB and BDNF and decreased mTOR levels, as well as augmented p-AMPK. In conclusion, we propose that Sildenafil alleviates EAE by activating autophagy via the eNOS-NO-AMPK-mTOR-LC3-beclin1-ATG5 and eNOS-NO-AMPK-mTOR-CREBBDNF pathways in the spinal cord.

Keywords: EAE (Experimental Autoimmune Encephalomyelitis), Sildenafil citrate (Viagra), neuroinflammation, autophagy, nitrosative stress 


\section{INTRODUCTION}

Multiple Sclerosis (MS) is a chronic neurodegenerative disease of the Central Nervous System (CNS) with a strong immuneinflammatory component underpinning is etiopathogenesis (1). Traditionally, MS has been characterized by demyelination, neuroaxonal degeneration and autoimmunity, which are the result of the activation of many transduction pathways, such as apoptosis, inflammation and excitotoxicity (2). Of note, the knowledge of these pathways is key to the development of new drugs to target MS or to repurpose the already available drugs.

Sildenafil is a Phosphodiesterase type 5 Inhibitor (PDE5I) widely used for erectile dysfunction (ED) (3), pulmonary hypertension (4) and Raynaud's Syndrome (5). Due to its pleiotropic effects, especially regarding neuroprotection and neuroimmunomodulation, this drug has been tested in other conditions such as neurodegenerative diseases and affective disorders, such as Alzheimer's Disease (AD) and Major Depressive Disorder (MDD) $(6,7)$, both of which have a strong immune-inflammatory component driving disease progression. The first study that showed the effects of Sildenafil in the Experimental Autoimmune Encephalomyelitis (EAE) model of MS was published by Pifarre et al. (8). In this study, Sildenafil at a dose of $10 \mathrm{mg} / \mathrm{kg}$ was administered subcutaneously (s.c.) after disease onset and the spinal cord was analyzed. However, a previous study by our group has shown that Sildenafil at a dose of $25 \mathrm{mg} / \mathrm{kg}$ s.c. also has neuroprotective effects because it inhibits demyelination, neuroinflammation and apoptosis in the spinal cord of EAE mice, which is directly related to the motor dysfunction observed in EAE mice (9). These different studies highlighted different aspects of the same pathology and contributed to our understanding of how the disease evolves and how it could be treated, since they also highlighted different molecular targets. Furthermore, we have also demonstrated similar findings in the cuprizone model of MS (10). More recently, we demonstrated that Sildenafil at the same dose and route of administration has neuroprotective effects in the hippocampus of EAE mice, since it reduced the number of infiltrating $\mathrm{T} \mathrm{CD}^{+}$lymphocytes, inhibited neuroinflammation and modulated synaptic plasticity and neurotransmission (11). However, other signaling pathways responsible for the mechanism of action of Sildenafil have not been explored. For instance, this is the case for autophagy, a cellular process essential to cell homeostasis and which is disrupted when there is an intense oxidative stress burden, causing the formation and accumulation of protein aggregates inside the cell. This ultimately compromises cell viability and leads to cell death $(12,13)$. Furthermore, autophagy is a key process in innate and adaptive immunity, in the regulation of inflammation, pathogen elimination and in MS pathogenesis (14-17). Moreover, studies have shown that autophagy is associated with neuroprotection against extra- and intracellular insults (18). Notably, in an animal model of depression induced by Chronic Unpredictable Mild Stress (CUMS), fluoxetine protected hippocampal astrocytes against stress-induced damage by promoting autophagy, which prevented cell death and contributed to the removal of damaged mitochondria (19). On the other hand, deficiency in autophagy observed in dopaminergic neurons may be a mechanism leading to increased susceptibility to cellular stress and neurodegeneration in Parkinson's Disease (PD) (20). Therefore, the aim of the present study was to further explore the signaling pathways underlying the mechanism of action of Sildenafil in EAE, focusing on nitrosative stress and autophagy pathways.

\section{MATERIALS AND METHODS}

\section{Animals}

Since MS is more prevalent in females than males (21), a total of 24 female C57BL/6 mice aged 8-12 weeks and weighing 25-30 g from Aggeu Magalhães Institute were used and distributed in the following experimental groups: a) CONTROL $(n=8)$ - mice that received only vehicle (water); b) EAE ( $n=8)$ - mice submitted to EAE induction and that received only vehicle (water); c) SILD $(n=8)$ - mice submitted to EAE induction during the daylight and that received $25 \mathrm{mg} / \mathrm{kg}$ of Sildenafil subcutaneously (s.c) during 21 days. Mice were kept under a controlled temperature $\left(22^{\circ} \mathrm{C}\right)$ and photoperiod environment $(12 \mathrm{~h} / 12 \mathrm{~h}$ light/dark) and received water and standard chow ad libitum throughout the entire experiment. The experiment was approved by and performed in accordance with the guidelines of the Aggeu Magalhães Institute Ethics Committee/Oswaldo Cruz Foundation (87/ 2015 CEUA/FIOCRUZ), which is in compliance with European (EU Directive 2010/63/EU) and American (National Institutes of Health guide for the care and use of Laboratory animals) standards. Moreover, CEUA/FIOCRUZ took into consideration the principle of the three Rs (reduction, replacement, and refinement) to approve the current number of mice.

\section{EAE Induction}

The EAE was induced as described elsewhere using naïve mice as controls (9). On the last day of the experiment, mice were anesthetized, and the spinal cord was harvested and used for the analysis of the nitrosative stress and autophagy pathways. All experiments were carried out in compliance with the ethical guidelines for animal experimentation (87/2015CEUA/FIOCRUZ).

\section{Sildenafil Treatment}

Sildenafil treatment $(25 \mathrm{mg} / \mathrm{kg}) \quad\left(V_{i a g r a}{ }^{\circledR}\right.$, Pfizer) was administered on day post-induction 3 for a total of 21 days always during the daytime as previously described (9).

\section{Immunohistochemistry (IHC)}

Immunohistochemistry was performed as previously described (9). Briefly, sections of all groups were incubated overnight at $4^{\circ} \mathrm{C}$ with the following primary antibodies: p-eNOS (Abcam, ab75639, 1:50), mTOR (Abcam, ab2732, 1:1000), Beclin-1 (Abcam, ab62557, 1:100), ATG5 (Abcam, ab228668, 1:100) and iNOS (Abcam, ab3523, 1:100. The labeling reaction was performed in six sections per group and the analysis of pixels quantification was performed in 6-8 images per group 
(mean value). Images of the same magnification were quantitatively analyzed using Gimp 2.6 software (GNU Image Manipulation Program, UNIX platforms). Unspecific labeling/ background was removed from the quantification by using the selection and exclusion tool of the aforementioned software.

\section{Western Blotting (WB)}

Protein extraction and Western blotting were performed as previously described elsewhere (9). Briefly, proteins (30 $\mu \mathrm{g}$ total) ( $\mathrm{n}=5$ spinal cords/per group) were separated with $12 \%$ acrylamide gel. After overnight incubation with 5\% non-fat milk, the membranes were incubated for four hours at room temperature with primary antibodies against p-AMPK (Cell Signaling, 2535S, 1:1000) followed by anti-rabbit HRPconjugated antibody (ABCAM, ab6721, 1:3000; SigmaAldrich). For quantification, the pixel density of each immunoblot was determined using the Image J 1.38 software (http://rsbweb.nih.gov/ij/download.html; developed by Wayne Rasband, NIH, Bethesda, MD, USA). The analyses were done in duplicate and immunoblotting for $\beta$-actin (1:1,000, SigmaAldrich, \#A2228) was performed as a loading control.

\section{Measurement of NO}

The Griess colorimetric assay was used to measure spinal cord levels of $\mathrm{NO}$ by the detection of nitrite $\left(\mathrm{NO}_{2}\right)$ resulting from oxidation of NO. Samples ( $n=5$ per group) were diluted fourfold with distilled water and deproteinized by adding $1 / 20$ volume of a zinc sulfate solution $(300 \mathrm{~g} / \mathrm{L})$, to give a final concentration of $15 \mathrm{~g} / \mathrm{L}$. Subsequently, centrifugation for $10 \mathrm{~min}$ at $3.500 \mathrm{~g}$ took place and $100 \mu \mathrm{L}$ of samples were added to a 96-well ELISA in triplicate, followed by the same volume of Griess reagent. The standard curve was prepared by serial dilution of a solution of sodium nitrite $(100 \mu \mathrm{M})$ was in PBS. After incubation for $10 \mathrm{~min}$ in the dark, the absorbance of the reaction product was read at $490 \mathrm{~nm}$ to allow information of nitrite concentration to be obtained. The absorbance of different samples was compared with the standard curve (22).

\section{Immunofluorescence of Paraffin- Embedded Tissue}

Immunofluorescence was performed as described elsewhere (9). Briefly, samples were incubated overnight at $4^{\circ} \mathrm{C}$ with anti-pCREB (Cell Signaling, \#9198, 1:100), anti-BDNF (Alomone, ANT-010, 1:100) and anti-MAP1LC3A/B antibody (Biorad, AHP2167, 1:100). The labeling reaction was performed in six sections per group and the analysis of pixels quantification was performed in 6-8 images per group (mean value). Images of the same magnification were quantitatively analyzed using Gimp 2.6 software (GNU Image Manipulation Program, UNIX platforms). Unspecific labeling/background was removed from the quantification by using the selection and exclusion tool of the aforementioned software.

\section{Statistical Analysis}

The statistical differences were analyzed by one-way ANOVA followed by Tukey's post-test and two-way ANOVA followed by Tukey's post-test (clinical score). The results are presented as mean \pm standard deviation. All analysis was done by using Graphpad Prism (version 6.0, GraphPad Software Inc., USA) software. A p-value $<0.05$ indicates statistical significance.

\section{RESULTS}

\section{Sildenafil Prevents the Development of Severe Motor Dysfunction in EAE Mice}

To assess whether the prophylactic administration of Sildenafil could prevent the development of motor dysfunction in EAE mice or even prevent a severe motor dysfunction, we evaluated mice daily to observe any changes in the motor function. Corroborating our previous findings, the control mice did not have any signs of motor dysfunction, which was only observed in the EAE mice. However, the prophylactic treatment with Sildenafil was able to prevent the progression of motor impairments (Figure 1, Supplementary Table 1).

\section{Sildenafil Decreases Nitrosative Stress Markers in the Spinal Cord of EAE Mice}

Oxidative and Nitrosative Stress (O\&NS) are known to be inducers of the autophagy process, as damaged molecules are constantly being generated due to cellular stress and removed by autophagy (23). However, when in excess nitrosative stress can lead to protein misfolding and aggregation, which contributes to neurodegeneration $(24,25)$. Taking that into consideration, drugs that have antioxidant effects can likely reduce excessive O\&NS and prevent their detrimental consequences. Therefore, we subsequently established whether Sildenafil could modulate

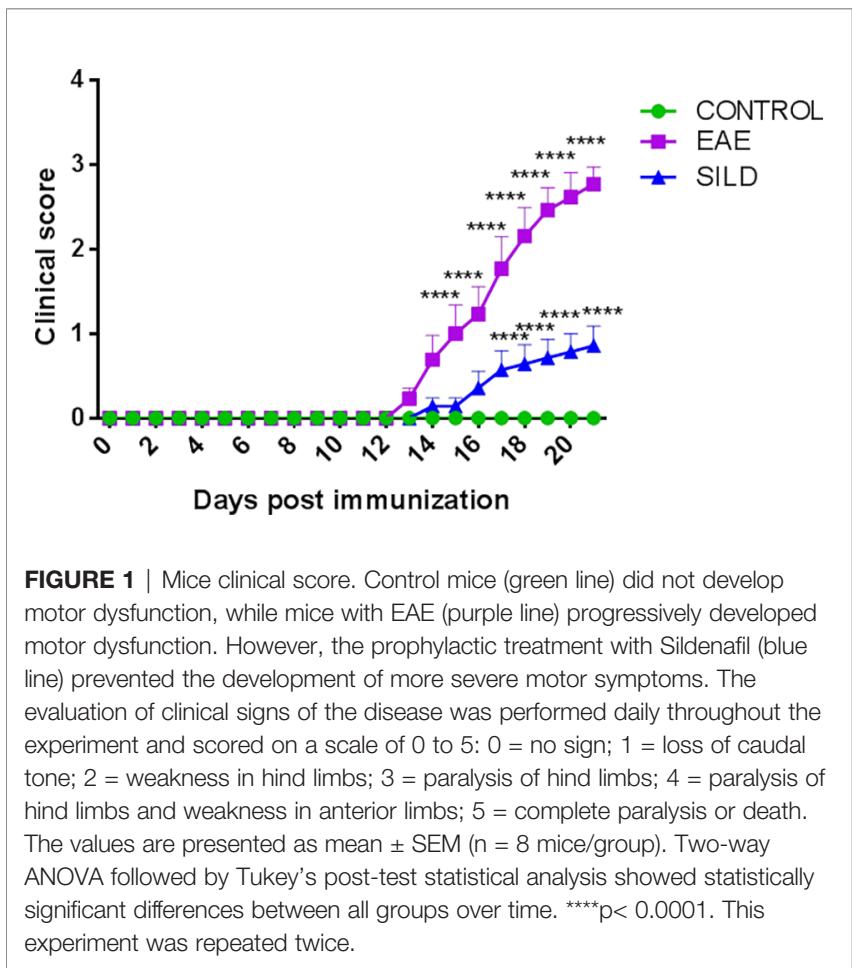


the nitrosative stress pathway using antibodies against p-eNOS, iNOS and measuring the levels of tissue nitrite $\left(\mathrm{NO}_{2}^{-}\right)$.

In the p-eNOs analysis, ANOVA analysis showed a significant difference among groups $(\mathrm{F}(2,15)=6.826, \mathrm{P}=$ $0.0078)$. The results showed that control mice had basal levels of p-eNOs. On the other hand, EAE mice presented decreased peNOS levels compared to control and sildenafil groups $(p<0.05)$ whereas the treatment with Sildenafil significantly augmented the p-eNOS levels compared to EAE group $(\mathrm{p}<0.05)$ (Figure 2A). The iNOS analysis showed statistical differences among groups by one-way ANOVA $(\mathrm{F}(2,23)=7.101, \mathrm{P}=0.0040)$. Control mice had basal levels of iNOS. On the one hand, the EAE group had increased levels of iNOS when compared to control group $(\mathrm{p}<0.01)$. By its turn, treatment with Sildenafil reduced iNOS levels compared with EAE group $(\mathrm{p}<0.05)$ (Figure $\mathbf{2 B}$, Supplementary Table 2).

Levels of nitrite in the spinal cord showed a difference among groups by one-way ANOVA $(\mathrm{F}(2,6)=13.72, \mathrm{P}=0.0058)$. Control group presented basal expression of $\mathrm{NO}$, while EAE mice had increased levels of nitrite compared with control group $(\mathrm{p}<0.01)$. Conversely, treatment with Sildenafil reduced nitrite levels compared to EAE group ( $\mathrm{p}<0.05)$ (Figure 4C).

\section{Sildenafil Modulates Autophagy Markers to Improve EAE}

The link between autophagy dysfunction and neurodegenerative diseases is well established. In many diseases, such as Parkinson's Disease (PD) and Alzheimer's Disease (AD), protein aggregation occurs due to the inability of the cellular machinery to remove them and this usually is accompanied by neurotoxicity and neurodegeneration (26). In the case of MS, it was experimentally demonstrated that protein aggregation contributes to neurodegeneration (12). In this regard, drugs that can target this pathway can likely be strong candidates to treat such diseases because they can likely remove protein aggregates and reestablish cellular proteostasis. To determine whether Sildenafil could modulate autophagy pathway, we used antibodies against autophagy and autophagy-related molecules, such as LC3, beclin1, ATG5, p-CREB, BDNF and mTOR.

Notably, we investigated whether Sildenafil could target the nucleation and elongation phase of autophagy characterized by the participation of LC3-beclin-1 and ATG5, respectively $(20,27)$. ANOVA analysis showed a significant difference among groups in $\operatorname{LC} 3(\mathrm{~F}(2,31)=8.718, \mathrm{P}=0.0010)$. EAE mice, on the one hand, had decreased levels of LC3 in comparison to control group $(\mathrm{p}<$ 0.05). On the other hand, treatment with Sildenafil increased LC3 levels when compared to untreated mice $(\mathrm{p}<0.01)$ (Figures 3B, F). In the beclin-1 analysis, ANOVA analysis showed a significant difference among groups $(\mathrm{F}(2,9)=11.05, \mathrm{P}=0.0038)$. Untreated mice had decreased expression of beclin-1 when compared to control mice $(p<0.01)$, which was reversed by treatment with Sildenafil $(\mathrm{p}<0.05)$ (Figures 3A, C). ANOVA analysis showed a significant difference among groups in ATG5 analysis $(\mathrm{F}(2,14)=$ 7.343, $\mathrm{P}=0.0066)$. On the one hand, untreated mice had diminished levels of ATG5 when compared to control group ( $\mathrm{p}<$ 0.05). On the other hand, Sildenafil augmented ATG5 levels when compared to the EAE group $(\mathrm{p}<0.01)$ (Figures $3 \mathbf{A}, \mathbf{D})$. ANOVA analysis showed a significant difference among groups in mTOR ( $F$ $(2,30)=4.817, \mathrm{P}=0.0153)$. EAE group had increased expression of $\mathrm{mTOR}$ in comparison to the control group $(\mathrm{p}<0.05)$, while mice

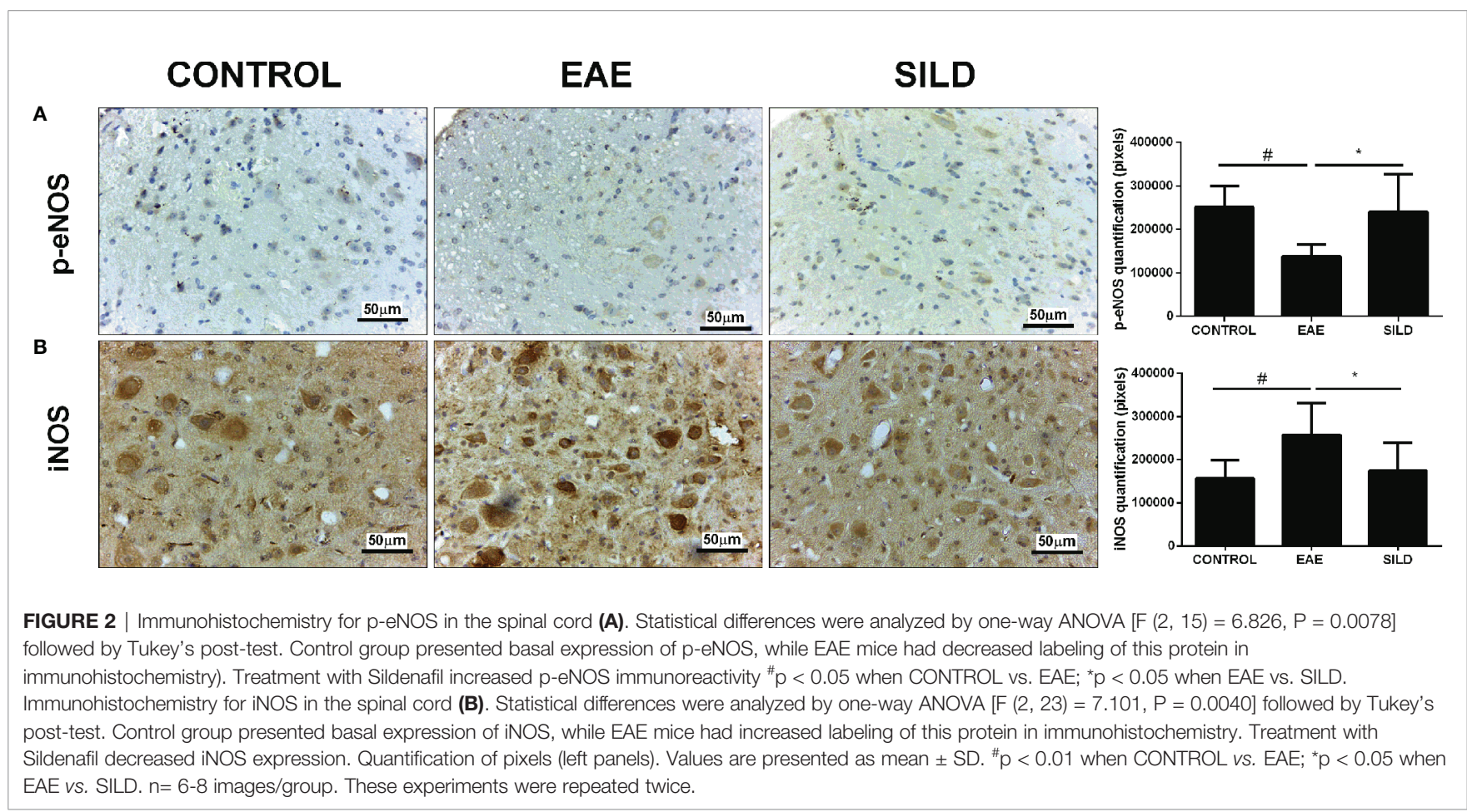


A

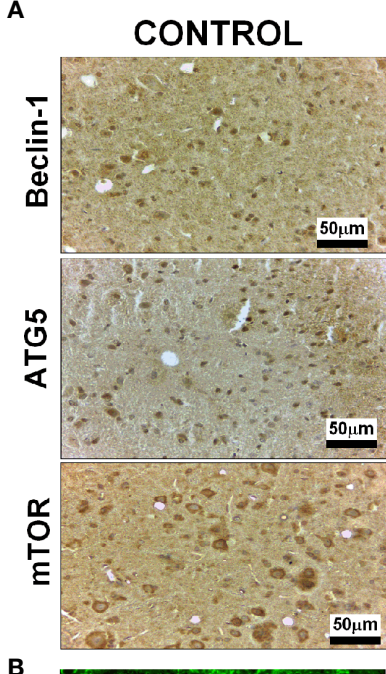

B
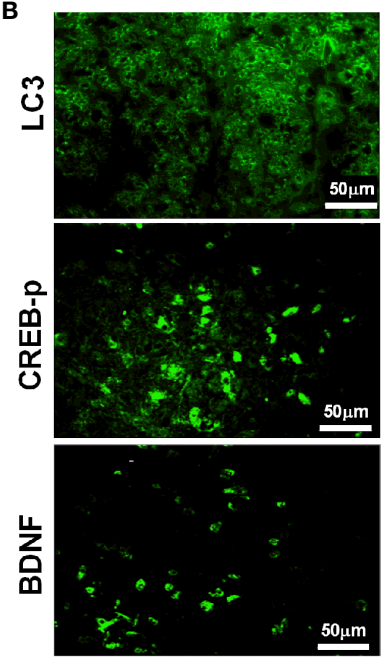

EAE
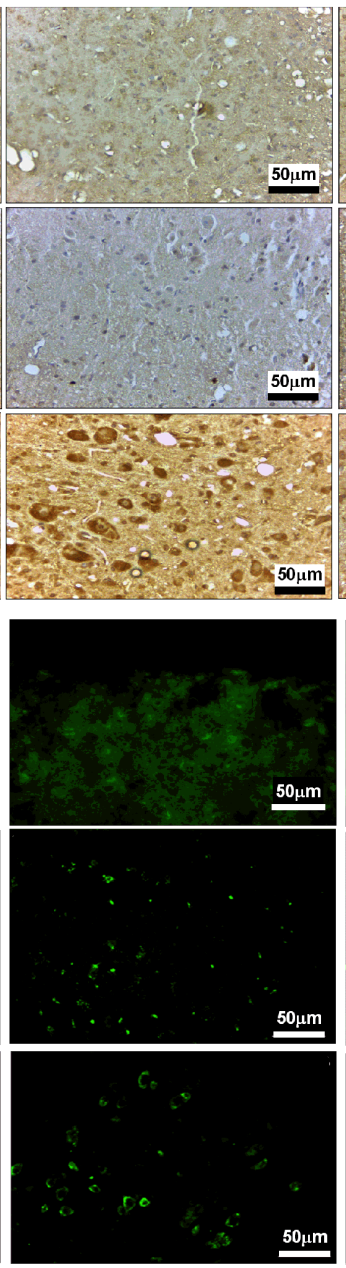

SILD
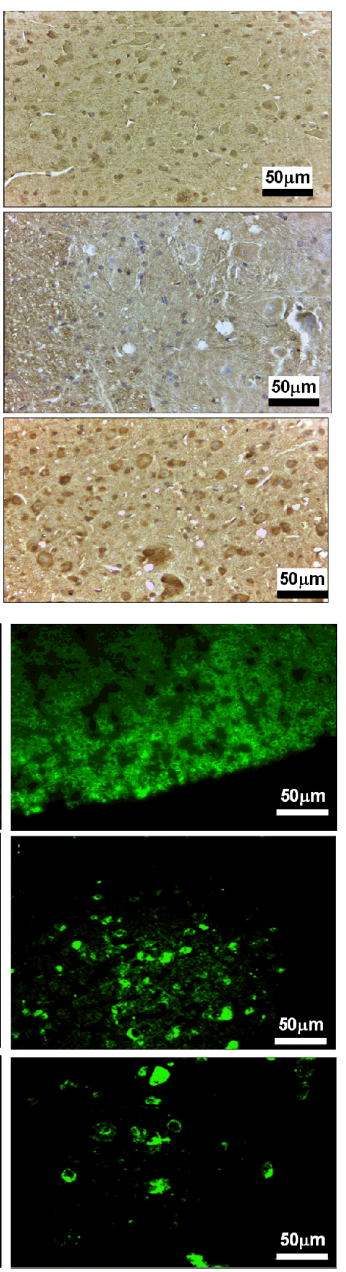

C

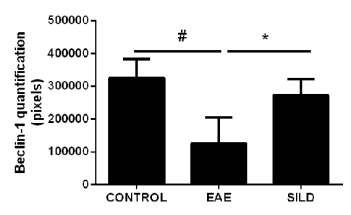

D

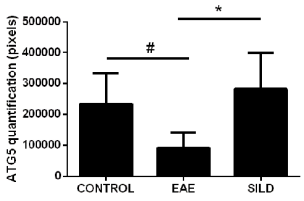

E

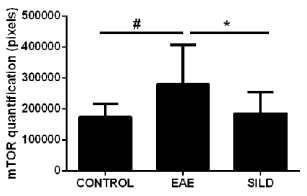

F

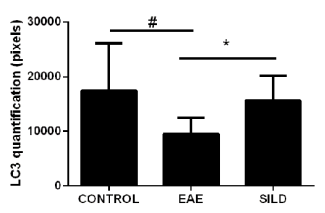

G

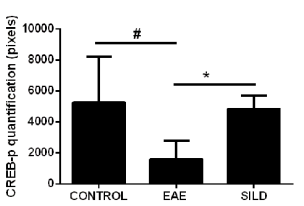

H

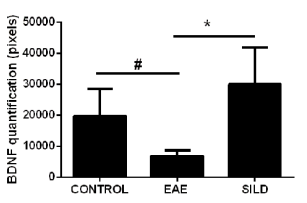

FIGURE 3 | (A) Immunohistochemistry for beclin-1 in the spinal cord. Statistical differences were analyzed by one-way ANOVA [F (2, 9) = 11.05, P = 0.0038] followed by Tukey's post-test. Control group presented basal expression of beclin-1, while EAE mice had decreased labeling of this protein in immunohistochemistry. Treatment with Sildenafil increased beclin-1 immunoreactivity. Immunohistochemistry for ATG5 in the spinal cord. Statistical differences were analyzed by one-way ANOVA $[F(2,14)=7.343, P=0.0066]$ followed by Tukey's post-test. Control group presented basal expression of ATG5, while EAE mice had decreased labeling of this protein in immunohistochemistry. Treatment with Sildenafil increased ATG5 immunoreactivity. Immunohistochemistry for mTOR in the spinal cord. Statistical differences were analyzed by one-way ANOVA $[F(2,30)=4.817, \mathrm{P}=0.0153]$ followed by Tukey's post-test. Control group presented basal expression of mTOR while EAE mice had increased labeling of this protein in immunohistochemistry. Treatment with Sildenafil decreased immunoreactivity mTOR immunoreactivity. (C-E) Quantification of pixels. Values are presented as mean \pm SD. ${ }^{*} p<0.05$ when CONTROL vs. EAE; * $<<0.01$ when EAE vs. SILD. $n=6-8$ images/group. These experiments were repeated twice. (B) Immunohistochemistry for LC3 in the spinal cord. Statistical differences were analyzed by one-way ANOVA [F (2, 31) = 8.718, $P=0.0010$ ] followed by Tukey's post-test. Control group presented basal expression of LC3, while EAE mice had decreased labeling of this protein in immunohistochemistry. Treatment with Sildenafil increased LC3 immunoreactivity. ${ }^{*} p<0.05$ when CONTROL vs. EAE; ${ }^{*} p<0.01$ when EAE vs. SILD. Immunohistochemistry for p-CREB in the spinal cord. Statistical differences were analyzed by one-way ANOVA [F (2, 10) = 6.987, P = 0.0126] followed by Tukey's post-test. Control group presented basal expression of $\mathrm{p}$-CREB, while EAE mice had decreased labeling of this protein. Treatment with Sildenafil increased p-CREB immunoreactivity. ${ }^{*} p<0.05$ when CONTROL vs. EAE; ${ }^{*} p<0.01$ when EAE vs. SILD. Immunohistochemistry for BDNF in the spinal cord. Statistical differences were analyzed by one-way ANOVA [F $(2,15)=14.26, \mathrm{P}=0.0003$ ] followed by Tukey's post-test. Control group presented basal expression of BDNF, while EAE mice had decreased labeling of this protein. Treatment with Sildenafil increased BDNF immunoreactivity. ${ }^{*} p<0.05$ when CONTROL vs. EAE; ${ }^{*} p<0.001$ when EAE vs. SILD (F-H) Quantification of pixels. Values are presented as mean \pm SD. $n=6-8$ images/group. These experiments were repeated twice.

that received Sildenafil had mTOR expression reduced $(\mathrm{p}<0.05)$ (Figures 3A, E, Supplementary Table 2).

Regarding p-CREB, ANOVA analysis showed a significant difference among groups $[\mathrm{F}(2,10)=6.987, \mathrm{P}=0.0126]$.
Untreated mice displayed reduced p-CREB levels in comparison to the control mice $(\mathrm{p}<0.05)$, while treatment with Sildenafil reversed this reduction $(\mathrm{p}<0.05)$ (Figures 3B, G). Finally, ANOVA analysis showed a significant difference among 
groups in $\mathrm{BDNF}[\mathrm{F}(2,15)=14.26, \mathrm{P}=0.0003]$. Untreated mice had lower levels of BDNF when compared to control group ( $\mathrm{p}<$ 0.05). However, treatment with Sildenafil increased BDNF levels in comparison to the EAE group $(\mathrm{p}<0.001)$ (Figures 3B, H, Supplementary Table 2).

\section{Sildenafil Modulates AMPK to Improve EAE}

AMP-activated protein kinase (AMPK) is not only an energy balance regulator, but it also plays a key role in the modulation of autophagy in an mTOR-dependent and independent fashion, such as via the modulation of the transcription factor Forkhead box O3 (FOXO3), known to induce the expression of autophagy genes, such as the ones that codify for beclin-1 and ATG5 (2830). In this regard, drugs that can modulate AMPK may be of relevance to achieve autophagy induction in neurodegenerative diseases. To establish whether Sildenafil could modulate the AMPK and thus indirectly modulate autophagy, we next used an antibody against p-AMPK. ANOVA analysis showed a significant difference among groups $(\mathrm{F}(2,3)=34.57, \mathrm{P}=$ $0.0085)$. The results showed that control mice had basal levels of $\mathrm{p}$-AMPK. Untreated mice, on the one hand, presented decreased levels of $\mathrm{p}$-AMPK when compared to control mice $(\mathrm{p}<0.01)$. Nonetheless, treatment with Sildenafil increased the levels of $\mathrm{p}$-AMPK in comparison to EAE mice $(\mathrm{p}<0.05)$ (Figures 4A, B).

\section{DISCUSSION}

In this study, we further investigated the molecular pathways underpinning the improvement observed in EAE mice treated with Sildenafil. Previously, we have demonstrated that Sildenafil decreases the clinical score of EAE mice by modulation of apoptotic pathways (9). Here, we corroborated this finding and demonstrated that this amelioration is also caused by the modulation of other signaling pathways, such as the nitrosative stress and autophagy pathways.

Dysfunction in the cellular redox status plays an important role in the pathogenesis of many diseases, including, but not limited to MS, Major Depressive Disorder (MDD) and Chagas disease (3133). Increased levels of Reactive Oxygen Species (ROS) as well as Reactive Nitrogen Species (RNS), such as Nitric Oxide (NO) and nitrite can be detrimental. ROS and RNS can react with proteins, lipids, and nucleic acids, causing damage to these molecules. Furthermore, by damaging the aforementioned molecules, ROS and RNS can generate neoepitopes against which an immune response can be mounted (31). Inducible Nitric Oxide Synthase (iNOS) is usually activated during inflammation and leads to high production of NO, within the micromolar range. It is noteworthy that NO can also be a source of RNS, which can damage the cellular constituents. Nitration of proteins is considered to be a mechanism driving disease progression in $\mathrm{AD}, \mathrm{PD}$ and Lateral Amyotrophic Sclerosis (ALS) $(34,35)$. However, not much is known about it in

A
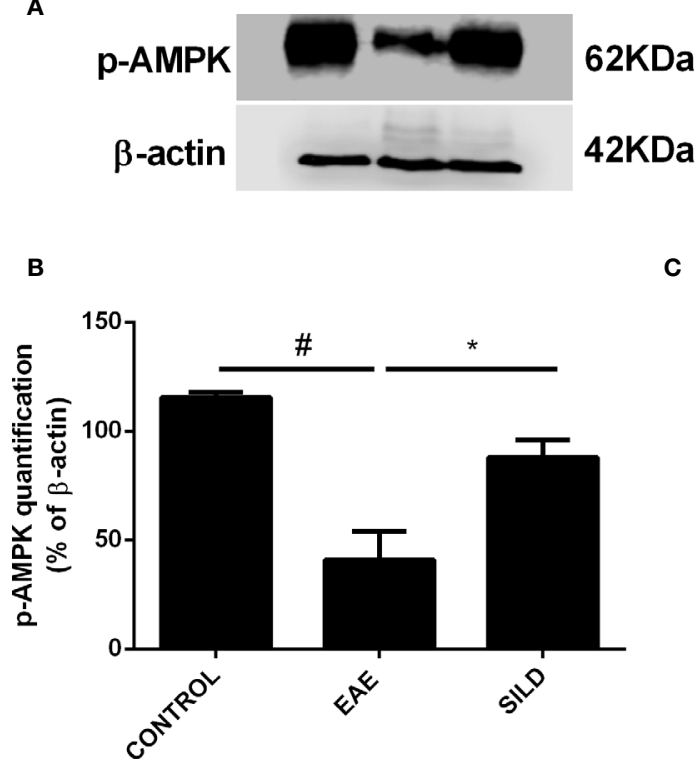

C

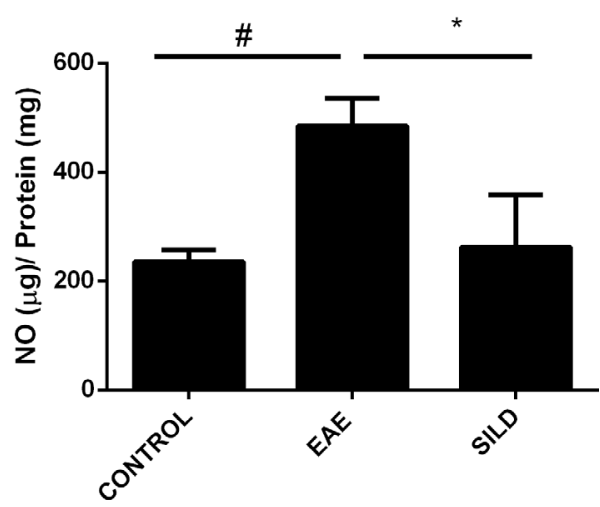

FIGURE 4 | Western blot for p-AMPK (A) Statistical differences were analyzed by one-way ANOVA $[F(2,3)=34.57, P=0.0085]$ followed by Tukey's post-test. Control group presented basal expression of p-AMPK, while EAE mice displayed decreased p-AMPK levels. Treatment with Sildenafil increased p-AMPK levels. (B) Densitometric analysis of $p$-AMPK. Values are presented as mean \pm SD. ${ }^{*} p<0.01$ when CONTROL vs. EAE; ${ }^{*} p<0.05$ when EAE vs. SILD $n=5$ mice/group. This experiment was repeated twice. (C) Levels of nitrite in the spinal cord showed difference among groups by one-way ANOVA $[F(2,6)=13.72, P=0.0058]$. Control group presented basal expression of NO, while EAE mice had increased levels of nitrite compared with control group. Conversely, treatment with Sildenafil reduced nitrite levels compared to EAE group. Values are presented as mean \pm SD. ${ }^{*} p<0.01$ when CONTROL vs. EAE; ${ }^{p} p<0.05$ when EAE vs. SILD. $n=5$ mice/ group. This experiment was repeated twice. 
the context of MS. NO can react with the cysteine residue of proteins by S-nitrosylation (SNO) and thereby affect protein structure and function, leading to their activation, deactivation or even aggregation, which is toxic to cells and drives neurodegeneration (36). Of key importance is when SNO modification occurs in pathways responsible for proteostasis and cytoprotection, such as the antioxidant and anti-apoptotic pathways. As a consequence, dysfunctional redox states and impaired autophagy facilitate protein aggregation and its permanence in the cell, affecting cell viability. In this regard, high amounts of NO facilitate the formation of protein aggregates $(36,37)$.

On the other hand, Endothelial Nitric Oxide Synthase (e-NOS) is responsible for basal NO production (nanomolar range), which regulates, for instance, vascular tone $(38,39)$. NO takes part in the NO-soluble guanylate cyclase (sGC)-Cyclic guanosine monophosphate (cGMP)-dependent protein kinase (PKG) pathway. Of note, accumulation of cGMP exerts antiinflammatory effects by reducing the levels of Intercellular Adhesion Molecule 1 (ICAM) and Vascular Cellular Adhesion Molecule (VCAM) in the cerebellum, which inhibits the traffic of leukocytes to the CNS (40). Furthermore, NO can also activate AMPK and reduce inflammation (41). Interestingly, AMPK is activated in response to IL-10 and favors macrophage polarization towards the anti-inflammatory or M2 phenotype (42). This is corroborated by our previous study (11) and this suggests that the switching of microglia to the M2 phenotype is probably due to the increased levels of IL-10 and p-AMPK in mice treated with Sildenafil. Furthermore, we showed that EAE is characterized by lowered expression of p-eNOS, but high levels of iNOS and NO, which favors nitrosative stress and protein aggregation. However, treatment with Sildenafil decreased iNOS and NO levels, while increasing the expression of eNOS.

It is worthy to mention that activated AMPK phosphorylates and activates eNOS, leading to NO production, which in turn activates AMPK $(41,43)$. Data have shown that oxidative and nitrosative stress (O\&NS) pathways play a key role in EAE and MS, characterized by high levels of oxidative stress markers as well as lowered levels of antioxidants (44-46). In a second vein, data have shown that Sildenafil is able to inhibit ROS and elevate the expression of antioxidant molecules, such as Superoxide Dismutase (SOD) and catalase (47). A previous study by our laboratory conducted with the cuprizone model of MS showed that Sildenafil led to increased levels of eNOS and p-AMPK (22). All in all, these data show that Sildenafil, when administered before disease symptoms, inhibits nitrosative stress and improves EAE. Furthermore, by stimulating eNOS, Sildenafil triggers the activation of the NO-sCG-cGMP-PKG pathway, which leads to the activation of AMPK.

AMPK is a protein known to be a regulator of energy balance. Interestingly, AMPK also regulates autophagy (48). Activated AMPK phosphorylates Tuberous Sclerosis 1 and 2 (TSC1/2) and inhibits mTORC1 complex, thus promoting autophagy (49). Furthermore, AMPK activation leads to inhibition of Nuclear Factor kappa B (NFkB) $(50,51)$. Moreover, activated AMPK also inhibits iNOS and thus inflammation (52). A study conducted in our laboratory has shown that Sildenafil increased the expression of p-AMPK in the cuprizone model of MS (22). In this regard, here we showed that EAE mice treated with Sildenafil presented increased levels of $\mathrm{p}$-AMPK, which further contributes to inhibition of neuroinflammation in the spinal cord. Interestingly, AMPK activated by $\mathrm{NO}$ phosphorylates $\mathrm{I} \kappa \mathrm{B}$ kinase (IKK) and prevents NFKB activation, thus exerting an anti-inflammatory effect (41). Furthermore, activated AMPK can indirectly inhibit NFKB by activating Sirtuin 1 (SIRT1), FOXO and Peroxisome Proliferator-Activated Receptor-Gamma Coactivator-1 $\alpha$ (PGC1 $\alpha)$ (49). In sum, our results suggest that activation of AMPK inhibits neuroinflammation and takes part in mTOR inhibition and autophagy induction. In fact, we reported here that Sildenafil increases p-AMPK and LC3 levels, while decreases mTOR levels, which likely suggests that Sildenafil favors and promotes autophagy in the spinal cord of EAE mice and thus exerts a neuroprotective effect.

Lower LC3-I/II and beclin-1 expression with consequent impaired autophagy were shown to occur in the spinal cord of EAE mice $(53,54)$ and induction of autophagy via the Cannabinoid Receptor 2 (CBR2) ameliorated EAE (55). Furthermore, it is reported that the expression of ATG5 is elevated in EAE (56), which is not corroborated by our findings and can likely be explained by differences in the analyzed samples and different stages of disease (purified $\mathrm{T}$ cells from EAE mice and postmortem brain tissue versus spinal cord as presented in this study). Here, we show that untreated mice had reduced levels of LC3, beclin-1 and ATG5 while showing an increase in mTOR expression. However, Sildenafil administration led to elevated expression of LC3, beclin-1 and ATG5, while displaying reduced mTOR levels. Furthermore, we previously reported increased IL-10 levels followed by Sildenafil treatment (11), which can further suppress the activity of mTOR and increase autophagy and mitophagy (57). Although the functional consequences of the activation of the autophagy pathways were not investigated here, one could reasonably argue that this process may lead to the removal of protein aggregates previously reported to occur during EAE and which are responsible for neuronal death by apoptosis $(12,13)$. Accordingly, we have previously demonstrated that during EAE the intrinsic and extrinsic pathways of apoptosis, as well as other signaling pathways that control cell survival/death, are activated, causing neuron death, which was rescued after Sildenafil treatment (9). Altogether, our results suggest that Sildenafil promotes autophagy and exerts neuroprotective effects by increasing IL-10 and AMPK levels and by modulating the expression of LC3, beclin-1 and ATG5 in the spinal cord of EAE mice.

The cAMP-response Element Binding Protein (CREB) is a transcription factor that binds to cAMP Response Element (CRE) and promotes transcription of target genes, including Brain Derived Neurotrophic Factor (BDNF), a neurotrophin that mediates neuroplasticity in the central and peripheral nervous system. Via CREB-BDNF pathway, neurons undergo neurogenesis, differentiation, survival, neurite outgrowth and synaptogenesis $(58,59)$. Interestingly, mTOR inhibition by rapamycin was accompanied by phosphorylation of CREB, 
which protected against neurodegeneration induced by amyloid$\beta$ (60). Furthermore, it is known that CREB can activate autophagy genes via the Farnesoid X receptor (FXR)/CREB signaling pathway whereby FXR inhibits CREB activation (6163). By its turn, AMPK inhibits FXR and thus increases CREB activation $(64,65)$. Regarding BDNF, it was shown that increased levels of BDNF were associated with inhibition of autophagy (66). However, other studies have shown that BDNF can also promote autophagy (67). In diabetic rats, BDNF-TrkB pathway exerted antidepressant effect of hydrogen sulfide $\left(\mathrm{H}_{2} \mathrm{~S}\right)$ by triggering autophagy in the hippocampus (68). In another study with cortical neurons submitted to oxygen deprivation in vitro, BDNF exerted neuroprotective effects by increasing autophagy via the $\mathrm{PI} 3 \mathrm{~K} / \mathrm{Akt} / \mathrm{mTOR} / \mathrm{p} 70 \mathrm{~S} 6 \mathrm{~K}$ pathway. Interestingly, BDNF administration led to decreased mTOR levels (69). Therefore, we postulate that the increased levels of CREB/BDNF may induce autophagy and ameliorate disease pathology and may also be involved in the reduction of mTOR expression, which could further trigger autophagy. However, future studies are needed to corroborate this hypothesis.

In summary, our data showed that Sildenafil ameliorates EAE by activating signaling pathways that mitigate nitrosative stress and by triggering autophagy pathway (Figure 5). However, the use of the subcutaneous route of administration has a clear translational limitation since Sildenafil is mainly taken via the oral route. Furthermore, despite the fact that PDE5Is are promising drugs to treat neurodegenerative disorders, Sildenafil is currently only prescribed to MS patients to treat ED (7, 38, 70-76). Moreover, only few clinical trials were performed to elucidate the efficacy and effects of these drugs. Notably, they have shown that treatment with PDE5Is led to enhanced cognitive performance and function (77-79) and improved overall life quality of the MS patients, which included life as a whole, family life and social contacts (80). However, the lack of clinical data makes it hard to ensure that MS patients taking these drugs would have a better prognosis. Therefore, future experimental studies, as well as clinical trials with MS patients, need to be performed to provide more insights into disease pathogenesis and disease progression. This would allow a more in-depth view of PDE5Is mechanism of action and how it could help in the treatment of neurodegenerative diseases, such as MS. In conclusion, we demonstrate that Sildenafil alleviates EAE via the eNOS-NO-AMPK-mTOR-LC3-beclin1ATG5 and eNOS-NO-AMPK-mTOR-CREB-BDNF pathways in the spinal cord, which triggers autophagy and consequently improves disease.

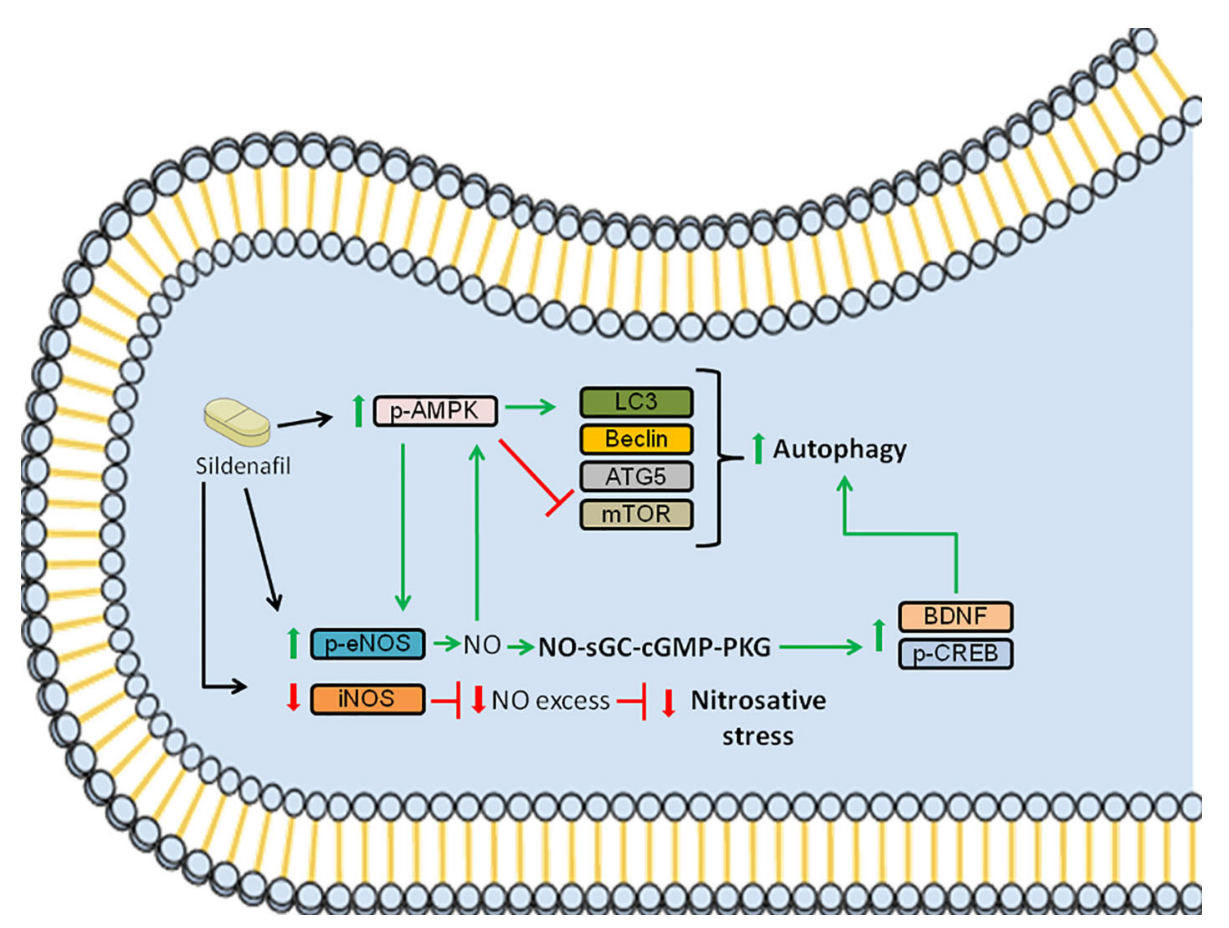

FIGURE 5 | Schematic summarizing the signaling pathways modulated by Sildenafil to improve EAE pathology. Sildenafil increases the levels of p-AMPK and reduces the levels of $\mathrm{mTOR}$, which leads to an increase in the levels of LC3, promoting autophagy. Furthermore, Sildenafil enhances the expression of $\mathrm{p}$-eNOS, leading to the production of NO, which further activates AMPK. Moreover, NO triggers the activation of the NO-sGC-cGMP-PKG pathway, which leads to increased levels of p-CREB and BDNF, further promoting autophagy. Furthermore, Sildenafil inhibits iNOS, which when activated produces NO in excess, thus inhibiting nitrosative stress. Altogether, the activation of the aforementioned signaling pathways improves EAE pathology. Red bars: inhibition; Green arrows: activation. 


\section{DATA AVAILABILITY STATEMENT}

The original contributions presented in the study are included in the article/Supplementary Material. Further inquiries can be directed to the corresponding authors.

\section{ETHICS STATEMENT}

The animal study was reviewed and approved by Aggeu Magalhães Institute Ethics Committee/Oswaldo Cruz Foundation (87/2015 CEUA/FIOCRUZ).

\section{AUTHOR CONTRIBUTIONS}

$\mathrm{CP}$ conceived and supervised this project. ED-S performed the experiment, literature search, data collection, data analysis, wrote the manuscript, and created the figures. SR, WO, DL, AB, GP, and LL provided help during the experiment and with sample processing. LV critically revised the manuscript. All authors approved the submitted version.

\section{REFERENCES}

1. Dendrou CA, Fugger L, Friese MA. Immunopathology of Multiple Sclerosis. Nat Rev Immunol (2015) 15:545-58. doi: 10.1038/nri3871

2. Faissner S, Plemel JR, Gold R, Yong VW. Progressive Multiple Sclerosis: From Pathophysiology to Therapeutic Strategies. Nat Rev Drug Discov (2019) 18:905-22. doi: 10.1038/s41573-019-0035-2

3. Fusco F, D’Anzeo G, Sessa A, Pace G, Rossi A, Capece M, et al. BPH/LUTS and ED: Common Pharmacological Pathways for a Common Treatment. J Sex Med (2013) 10:2382-93. doi: 10.1111/jsm.12261

4. Zhao L, Mason NA, Strange JW, Walker H, Wilkins MR. Beneficial Effects of Phosphodiesterase 5 Inhibition in Pulmonary Hypertension are Influenced by Natriuretic Peptide Activity. Circulation (2003) 2:234-7. doi: 10.1161/ 01.CIR.0000050653.10758.6B

5. Fries R, Shariat K, von Wilmowsky H, Böhm M. Sildenafil in the Treatment of Raynaud's Phenomenon Resistant to Vasodilatory Therapy. Circulation (2005) 112:2980-5. doi: 10.1161/CIRCULATIONAHA.104.523324

6. Duarte-Silva E, Filho AJMC, Barichello T, Quevedo J, Macedo D, Peixoto C. Phosphodiesterase-5 Inhibitors: Shedding New Light on the Darkness of Depression? J Affect Disord (2020) 264:138-49. doi: 10.1016/j.jad.2019.11.114

7. Puzzo D, Loreto C, Giunta S, Musumeci G, Frasca G, Podda MV, et al. Effect of Phosphodiesterase-5 Inhibition on Apoptosis and Beta Amyloid Load in Aged Mice. Neurobiol Aging (2014) 35:520-31. doi: 10.1016/j.neurobiolaging.2013.09.002

8. Pifarre P, Prado J, Baltrons MA, Giralt M, Gabarro P, Feinstein DL, et al. Sildenafil (Viagra) Ameliorates Clinical Symptoms and Neuropathology in a Mouse Model of Multiple Sclerosis. Acta Neuropathol (2011) 121:499-508. doi: 10.1007/s00401-010-0795-6

9. Duarte-Silva E, Araújo SM da R, Oliveira WH, Lós DBD, França MERD, Bonfanti AP, et al. Sildenafil Ameliorates EAE by Decreasing Apoptosis in the Spinal Cord of C57BL/6 Mice. J Neuroimmunol (2018) 321:125-37. doi: 10.1016/j.jneuroim.2018.06.002

10. Nunes AKDS, Rapôso C, Luna RLDA, Cruz-Höfling MAD, Peixoto CA. Sildenafil (Viagra ${ }^{\circledR}$ ) Down Regulates Cytokines and Prevents Demyelination in a Cuprizone-Induced MS Mouse Model. Cytokine (2012) 60:540-51. doi: 10.1016/j.cyto.2012.06.011

11. Araújo SMDR, Duarte-Silva E, Marinho CGDS, Oliveira WH, França MERD, Lós D, et al. Effect of Sildenafil on Neuroinflammation and Synaptic Plasticity Pathways in Experimental Autoimmune Encephalomyelitis. Int Immunopharmacol (2020) 85:106581. doi: 10.1016/j.intimp.2020.106581

\section{FUNDING}

The authors express their gratitude to Oswaldo Cruz Foundation of Pernambuco (FIOCRUZ-PE), Research Excellence Program Aggeu Magalhães Institute (IAM PROEP\#400208/2019-9), Knowledge Generation Program - Oswaldo Cruz Foundation (FIOCRUZ; \#VPPCB-007-FIO-18-2-17), The Brazilian National Institute of Science and Technology on Neuroimmunomodulation (INCT-NIM; \#465489/2014-1), and Brazilian National Council for Scientific and Technological Development (CNPq; \#301777/ 2012-8) for research support. This study was funded in part by the Coordenação de Aperfeiçoamento de Pessoal de Nível Superior Brasil (CAPES) - Finance Code 001. The funders had no role in study design, data collection and analysis, decision to publish, or preparation of the manuscript.

\section{SUPPLEMENTARY MATERIAL}

The Supplementary Material for this article can be found online at: https://www.frontiersin.org/articles/10.3389/fimmu.2021. 671511/full\#supplementary-material

12. Dasgupta A, Zheng J, Perrone-Bizzozero NI, Bizzozero OA. Increased Carbonylation, Protein Aggregation and Apoptosis in the Spinal Cord of Mice With Experimental Autoimmune Encephalomyelitis. ASN Neuro (2013) 5:e00111. doi: 10.1042/AN20120088

13. Dasgupta A, Zheng J, Bizzozero OA. Protein Carbonylation and Aggregation Precede Neuronal Apoptosis Induced by Partial Glutathione Depletion. ASN Neuro (2012) 4:161-74. doi: 10.1042/AN20110064

14. Deretic V, Saitoh T, Akira S. Autophagy in Infection, Inflammation and Immunity. Nat Rev Immunol (2013) 13:722-37. doi: 10.1038/nri3532

15. Keller CW, Lünemann JD. Autophagy and Autophagy-Related Proteins in CNS Autoimmunity. Front Immunol (2017) 8:165. doi: 10.3389/fimmu. 2017.00165

16. Hassanpour M, Hajihassani F, Hiradfar A, Aghamohammadzadeh N, Rahbarghazi R, Safaie N, et al. Real-State of Autophagy Signaling Pathway in Neurodegenerative Disease; Focus on Multiple Sclerosis. J Inflamm (United Kingdom) (2020) 17:6. doi: 10.1186/s12950-020-0237-8

17. Yin H, Wu H, Chen Y, Zhang J, Zheng M, Chen G, et al. The Therapeutic and Pathogenic Role of Autophagy in Autoimmune Diseases. Front Immunol (2018) 9:1512. doi: 10.3389/fimmu.2018.01512

18. Glick D, Barth S, Macleod KF. Autophagy: Cellular and Molecular Mechanisms. J Pathol (2010) 221:3-12. doi: 10.1002/path.2697

19. Shu X, Sun Y, Sun X, Zhou Y, Bian Y, Shu Z, et al. The Effect of Fluoxetine on Astrocyte Autophagy Flux and Injured Mitochondria Clearance in a Mouse Model of Depression. Cell Death Dis (2019) 10:557. doi: 10.1038/s41419-019-1813-9

20. Wise JP, Price CG, Amaro JA, Cannon JR. Autophagy Disruptions Associated With Altered Optineurin Expression in Extranigral Regions in a Rotenone Model of Parkinson's Disease. Front Neurosci (2018) 12:289. doi: 10.3389/ fnins.2018.00289

21. Wallin MT, Culpepper WJ, Nichols E, Bhutta ZA, Gebrehiwot TT, Hay SI, et al. Global, Regional, and National Burden of Multiple Sclerosis 1990-2016: A Systematic Analysis for the Global Burden of Disease Study 2016. Lancet Neurol (2019) 18:269-85. doi: 10.1016/S1474-4422(18)30443-5

22. Nunes AKS, Rapôso C, Rocha SWS, Barbosa KPDS, de Almeida Luna RL, da Cruz-Höfling MA, et al. Involvement of AMPK, IK $\beta \alpha-N F \kappa B$ and eNOS in the Sildenafil Anti-Inflammatory Mechanism in a Demyelination Model. Brain Res (2015) 1627:119-33. doi: 10.1016/j.brainres.2015.09.008

23. Filomeni G, De Zio D, Cecconi F. Oxidative Stress and Autophagy: The Clash Between Damage and Metabolic Needs. Cell Death Differ (2015) 22:377-88. doi: $10.1038 / \mathrm{cdd} .2014 .150$ 
24. Gu Z, Nakamura T, Lipton SA. Redox Reactions Induced by Nitrosative Stress Mediate Protein Misfolding and Mitochondrial Dysfunction in Neurodegenerative Diseases. Mol Neurobiol (2010) 41:55-72. doi: 10.1007/ s12035-010-8113-9

25. Nakamura T, Lipton SA. Molecular Mechanisms of Nitrosative StressMediated Protein Misfolding in Neurodegenerative Diseases. Cell Mol Life Sci (2007) 64:1609-20. doi: 10.1007/s00018-007-6525-0

26. Kurtishi A, Rosen B, Patil KS, Alves GW, Møller SG. Cellular Proteostasis in Neurodegeneration. Mol Neurobiol (2019) 56:3676-89. doi: 10.1007/s12035018-1334-Z

27. Cheng Z. The FoxO-Autophagy Axis in Health and Disease. Trends Endocrinol Metab (2019) 30:658-71. doi: 10.1016/j.tem.2019.07.009

28. Mihaylova MM, Shaw RJ. The AMPK Signalling Pathway Coordinates Cell Growth, Autophagy and Metabolism. Nat Cell Biol (2011) 13:1016-23. doi: $10.1038 /$ ncb2329

29. Greer EL, Oskoui PR, Banko MR, Maniar JM, Gygi MP, Gygi SP, et al. The Energy Sensor AMP-activated Protein Kinase Directly Regulates the Mammalian FOXO3 Transcription Factor. J Biol Chem (2007) 282:3010719. doi: $10.1074 /$ jbc.M705325200

30. Audesse AJ, Dhakal S, Hassell LA, Gardell Z, Nemtsova Y, Webb AE. FOXO3 Directly Regulates an Autophagy Network to Functionally Regulate Proteostasis in Adult Neural Stem Cells. PloS Genet (2019) 15:e1008097. doi: 10.1371/journal.pgen.1008097

31. Moylan S, Berk M, Dean OM, Samuni Y, Williams LJ, O’Neil A, et al. Oxidative \& Nitrosative Stress in Depression: Why So Much Stress? Neurosci Biobehav Rev (2014) 45:46-62. doi: 10.1016/j.neubiorev.2014.05.007

32. Kallaur AP, Lopes J, Oliveira SR, Simão ANC, Reiche EMV, de Almeida ERD, et al. Immune-Inflammatory and Oxidative and Nitrosative Stress Biomarkers of Depression Symptoms in Subjects With Multiple Sclerosis: Increased Peripheral Inflammation But Less Acute Neuroinflammation. Mol Neurobiol (2016) 53:5191-202. doi: 10.1007/s12035-015-9443-4

33. Duarte-Silva E, Maes M, Macedo D, Savino W, Peixoto CA. Shared Neuroimmune and Oxidative Pathways Underpinning Chagas Disease and Major Depressive Disorder. Transl Psychiatry (2020) 10:419. doi: 10.1038/ s41398-020-01105-9

34. Martínez A, Portero-Otin M, Pamplona R, Ferrer I. Protein Targets of Oxidative Damage in Human Neurodegenerative Diseases With Abnormal Protein Aggregates. Brain Pathol (2010) 20:281-97. doi: 10.1111/j.17503639.2009.00326.x

35. Chung KKK. Say NO to Neurodegeneration: Role of S-nitrosylation in Neurodegenerative Disorders. NeuroSignals (2007) 15:307-13. doi: 10.1159/ 000109071

36. Chung KKK, David KK. Emerging Roles of Nitric Oxide in Neurodegeneration. Nitric Oxide (2010) 22:290-5. doi: 10.1016/j.niox.2010.02.002

37. Tegeder I. Nitric Oxide Mediated Redox Regulation of Protein Homeostasis. Cell Signal (2019) 53:348-56. doi: 10.1016/j.cellsig.2018.10.019

38. Peixoto CA, Nunes AKS, Garcia-Osta A. Phosphodiesterase-5 Inhibitors: Action on the Signaling Pathways of Neuroinflammation, Neurodegeneration, and Cognition. Mediators Inflamm (2015) 2015:940207. doi: $10.1155 / 2015 / 940207$

39. Green SJ, Scheller LF, Marletta MA, Seguin MC, Klotz FW, Slayter M, et al. Nitric Oxide: Cytokine-regulation of Nitric Oxide in Host Resistance to Intracellular Pathogens. Immunol Lett (1994) 43:87-94. doi: 10.1016/01652478(94)00158-8

40. Rapôso C, Luna RL de A, Nunes AKS, Thomé R, Peixoto CA. Role of iNOS-NOcGMP Signaling in Modulation of Inflammatory and Myelination Processes. Brain Res Bull (2014) 104:60-73. doi: 10.1016/j.brainresbull.2014.04.002

41. Bess E, Fisslthaler B, Frömel T, Fleming I. Nitric Oxide-Induced Activation of the AMP-activated Protein Kinase $\alpha 2$ Subunit Attenuates IкB Kinase Activity and Inflammatory Responses in Endothelial Cells. PloS One (2011) 6:e20848. doi: 10.1371/journal.pone.0020848

42. Zhu YP, Brown JR, Sag D, Zhang L, Suttles J. Adenosine 5'-MonophosphateActivated Protein Kinase Regulates IL-10-mediated Anti-Inflammatory Signaling Pathways in Macrophages. J Immunol (2015) 194:584-94. doi: 10.4049/jimmunol.1401024

43. Chen Z, Peng IC, Sun W, Su MI, Hsu PH, Fu Y, et al. AMP-Activated Protein Kinase Functionally Phosphorylates Endothelial Nitric Oxide Synthase Ser633. Circ Res (2009) 104:496-505. doi: 10.1161/CIRCRESAHA.108.187567
44. Miller E, Walczak A, Saluk J, Ponczek MB, Majsterek I. Oxidative Modification of Patient's Plasma Proteins and its Role in Pathogenesis of Multiple Sclerosis. Clin Biochem (2012) 45:26-30. doi: 10.1016/j.clinbiochem.2011.09.021

45. Tasset I, Agüera E, Sánchez-López F, Feijóo M, Giraldo AI, Cruz AH, et al. Peripheral Oxidative Stress in Relapsing-Remitting Multiple Sclerosis. Clin Biochem (2012) 45:440-4. doi: 10.1016/j.clinbiochem.2012.01.023

46. Escribano BM, Medina-Fernández FJ, Aguilar-Luque M, Agüera E, Feijoo M, Garcia-Maceira FI, et al. Lipopolysaccharide Binding Protein and Oxidative Stress in a Multiple Sclerosis Model. Neurotherapeutics (2017) 14:199-211. doi: 10.1007/s13311-016-0480-0

47. Sikandaner HE, Park SY, Kim MJ, Park SN, Yang DW. Neuroprotective Effects of Sildenafil Against Oxidative Stress and Memory Dysfunction in Mice Exposed to Noise Stress. Behav Brain Res (2017) 319:37-47. doi: 10.1016/j.bbr.2016.10.046

48. Garcia D, Shaw RJ. AMPK: Mechanisms of Cellular Energy Sensing and Restoration of Metabolic Balance. Mol Cell (2017) 66:789-800. doi: 10.1016/ j.molcel.2017.05.032

49. Peixoto CA, de OWH, Araújo SM da R, Nunes AKS. AMPK Activation: Role in the Signaling Pathways of Neuroinflammation and Neurodegeneration. Exp Neurol (2017) 298:31-41. doi: 10.1016/j.expneurol.2017.08.013

50. Huang BP, Lin CH, Chen HM, Lin JT, Cheng YF, Kao SH. AMPK Activation Inhibits Expression of Proinflammatory Mediators Through Downregulation of PI3K/p38 MAPK and NF-אB Signaling in Murine Macrophages. DNA Cell Biol (2015) 34:133-41. doi: 10.1089/dna.2014.2630

51. Salminen A, Hyttinen JM, Kaarniranta K. AMP-Activated Protein Kinase Inhibits NF-kappaB Signaling and Inflammation: Impact on Healthspan and Lifespan 3366. J Mol Med (Berl) (2011) 89:667-76. doi: 10.1007/s00109-011-0748-0

52. Pilon G, Dallaire P, Marette A. Inhibition of Inducible Nitric-Oxide Synthase by Activators of AMP-activated Protein Kinase: A New Mechanism of Action of Insulin-Sensitizing Drugs. J Biol Chem (2004) 279:20767-74. doi: 10.1074/ jbc.M401390200

53. Feng X, Hou H, Zou Y, Guo L. Defective Autophagy is Associated With Neuronal Injury in a Mouse Model of Multiple Sclerosis. Bosn J Basic Med Sci (2017) 17:95-103. doi: 10.17305/bjbms.2017.1696

54. Boyao Y, Mengjiao S, Caicai B, Xiaoling L, Zhenxing L, Manxia W. Dynamic Expression of Autophagy-Related Factors in Autoimmune Encephalomyelitis and Exploration of Curcumin Therapy. J Neuroimmunol (2019) 337:577067. doi: 10.1016/j.jneuroim.2019.577067

55. Shao BZ, Wei W, Ke P, Xu ZQ, Zhou JX, Liu C. Activating Cannabinoid Receptor 2 Alleviates Pathogenesis of Experimental Autoimmune Encephalomyelitis Via Activation of Autophagy and Inhibiting NLRP3 Inflammasome. CNS Neurosci Ther (2014) 20:1021-8. doi: 10.1111/cns.12349

56. Alirezaei M, Fox HS, Flynn CT, Moore CS, Hebb ALO, Frausto RF, et al. Elevated ATG5 Expression in Autoimmune Demyelination and Multiple Sclerosis. Autophagy (2009) 5:152-8. doi: 10.4161/auto.5.2.7348

57. Ip WKE, Hoshi N, Shouval DS, Snapper S, Medzhitov R. Anti-Inflammatory Effect of IL-10 Mediated by Metabolic Reprogramming of Macrophages. Science (80- ) (2017) 356:513-9. doi: 10.1126/science.aal3535

58. Finkbeiner S. CREB Couples Neurotrophin Signals to Survival Messages. Neuron (2000) 25:11-4. doi: 10.1016/S0896-6273(00)80866-1

59. Finkbeiner S, Tavazoie SF, Maloratsky A, Jacobs KM, Harris KM, Greenberg ME. CREB: A Major Mediator of Neuronal Neurotrophin Responses. Neuron (1997) 19:1031-47. doi: 10.1016/S0896-6273(00)80395-5

60. Singh AK, Kashyap MP, Tripathi VK, Singh S, Garg G, Rizvi SI. Neuroprotection Through Rapamycin-Induced Activation of Autophagy and PI3K/Akt1/mTOR/ CREB Signaling Against Amyloid- $\beta$-Induced Oxidative Stress, Synaptic/ Neurotransmission Dysfunction, and Neurodegeneration in Adult Rats. Mol Neurobiol (2017) 54:5815-28. doi: 10.1007/s12035-016-0129-3

61. Füllgrabe J, Ghislat G, Cho DH, Rubinsztein DC. Transcriptional Regulation of Mammalian Autophagy At a Glance. J Cell Sci (2016) 129:3059-66. doi: $10.1242 /$ jcs. 188920

62. Seok S, Fu T, Choi SE, Li Y, Zhu R, Kumar S, et al. Transcriptional Regulation of Autophagy by an FXR-CREB Axis. Nature (2014) 516:108-11. doi: 10.1038/ nature13949

63. Di Malta C, Cinque L, Settembre C. Transcriptional Regulation of Autophagy: Mechanisms and Diseases. Front Cell Dev Biol (2019) 7:114. doi: 10.3389/ fcell.2019.00114

64. Keshk WA, Soliman NA, Ali DA, Elseady WS. Mechanistic Evaluation of AMPK/SIRT1/FXR Signaling Axis, Inflammation, and Redox Status in 
Thioacetamide-Induced Liver Cirrhosis: The Role of Cichorium Intybus Linn (Chicory)-Supplemented Diet. J Food Biochem (2019) 43:e12938. doi: 10.1111/jfbc.12938

65. Zheng L, Yin L, Xu L, Qi Y, Li H, Xu Y, et al. Protective Effect of Dioscin Against Thioacetamide-Induced Acute Liver Injury Via FXR/AMPK Signaling Pathway In Vivo. BioMed Pharmacother (2018) 97:481-8. doi: 10.1016/ j.biopha.2017.10.153

66. Nikoletopoulou V, Sidiropoulou K, Kallergi E, Dalezios Y, Tavernarakis N. Modulation of Autophagy by BDNF Underlies Synaptic Plasticity. Cell Metab (2017) 26:230-42.e5. doi: 10.1016/j.cmet.2017.06.005

67. Ducaji EC, Pareja-Cajiao M, Gransee HM, Sieck GC, Mantilla CB. BDNF/ TrkB Signaling Increases Autophagy Flux in Cervical Spinal Cord. FASEB J (2020) 34:1-1. doi: 10.1096/fasebj.2020.34.s1.05305

68. Liu HY, Wei HJ, Wu L, Liu SM, Tang YY, Zou W, et al. BDNF-TrkB Pathway Mediates Antidepressant-Like Roles of H2S in Diabetic Rats Via Promoting Hippocampal Autophagy. Clin Exp Pharmacol Physiol (2020) 47:302-12. doi: $10.1111 / 1440-1681.13201$

69. Chen A, Xiong LJ, Tong Y, Mao M. Neuroprotective Effect of Brain-Derived Neurotrophic Factor Mediated by Autophagy Through the PI3K/Akt/mTOR Pathway. Mol Med Rep (2013) 8:1011-6. doi: 10.3892/mmr.2013.1628

70. Nabavi SM, Talarek S, Listos J, Nabavi SF, Devi KP, Roberto de Oliveira M, et al. Phosphodiesterase Inhibitors Say NO to Alzheimer's Disease. Food Chem Toxicol (2019) 134:110822. doi: 10.1016/j.fct.2019.110822

71. Sanders O, Rajagopal L. Phosphodiesterase Inhibitors for Alzheimer's Disease: A Systematic Review of Clinical Trials and Epidemiology With a Mechanistic Rationale. J Alzheimers Dis Rep (2020) 4:185-215. doi: 10.3233/adr-200191

72. García-Osta A, Cuadrado-Tejedor M, García-Barroso C, Oyarzábal J, Franco R. Phosphodiesterases as Therapeutic Targets for Alzheimer's Disease. ACS Chem Neurosci (2012) 3:832-44. doi: 10.1021/cn3000907

73. Puzzo D, Staniszewski A, Shi XD, Privitera L, Leznik E, Liu SM, et al. Phosphodiesterase 5 Inhibition Improves Synaptic Function, Memory, and Amyloid-beta Load in an Alzheimer's Disease Mouse Model. J Neurosci (2009) 29:8075-6. doi: 10.1523/Jneurosci.0864-09.2009

74. Cuadrado-Tejedor M, Hervias I, Ricobaraza A, Puerta E, Pérez-Roldán JM, García-Barroso C, et al. Sildenafil Restores Cognitive Function Without Affecting $\beta$-Amyloid Burden in a Mouse Model of Alzheimer's Disease. $\mathrm{Br} J$ Pharmacol (2011) 164:2029-41. doi: 10.1111/j.1476-5381.2011.01517.x
75. Zhang J, Guo J, Zhao X, Chen Z, Wang G, Liu A, et al. Phosphodiesterase-5 Inhibitor Sildenafil Prevents Neuroinflammation, Lowers Beta-Amyloid Levels and Improves Cognitive Performance in APP/PS1 Transgenic Mice. Behav Brain Res (2013) 250:230-7. doi: 10.1016/j.bbr.2013.05.017

76. García-Barroso C, Ricobaraza A, Pascual-Lucas M, Unceta N, Rico AJ, Goicolea MA, et al. Tadalafil Crosses the Blood-Brain Barrier and Reverses Cognitive Dysfunction in a Mouse Model of AD. Neuropharmacology (2013) 64:114-23. doi: 10.1016/j.neuropharm.2012.06.052

77. Schultheiss D. Central Effects of Sildenafil (Viagra) on Auditory Selective Attention and Verbal Recognition Memory in Humans: A Study With EventRelated Brain Potentials. World J Urol (2001) 19:46-50. doi: 10.1007/ PL00007092

78. Shim YS, Pae CU, Kim SW, Kim HW, Kim JC, Koh JS. Effects of Repeated Dosing With Udenafil (Zydena) on Cognition, Somatization and Erection in Patients With Erectile Dysfunction: A Pilot Study. Int J Impot Res (2011) 23:109-14. doi: 10.1038/ijir.2011.13

79. Shim YS, Pae CU, Cho KJ, Kim SW, Kim JC, Koh JS. Effects of Daily LowDose Treatment With Phosphodiesterase Type 5 Inhibitor on Cognition, Depression, Somatization and Erectile Function in Patients With Erectile Dysfunction: A Double-Blind, Placebo-Controlled Study. Int J Impot Res (2014) 26:76-80. doi: 10.1038/ijir.2013.38

80. Fowler CJ, Miller JR, Sharief MK, Hussain IF, Stecher VJ, Sweeney M. A Double Blind, Randomised Study of Sildenafil Citrate for Erectile Dysfunction in Men With Multiple Sclerosis. J Neurol Neurosurg Psychiatry (2005) 76:7005. doi: 10.1136/jnnp.2004.038695

Conflict of Interest: The authors declare that the research was conducted in the absence of any commercial or financial relationships that could be construed as a potential conflict of interest.

Copyright (C) 2021 Duarte-Silva, Meiry da Rocha Araújo, Oliveira, Lós, Bonfanti, Peron, de Lima Thomaz, Verinaud and Peixoto. This is an open-access article distributed under the terms of the Creative Commons Attribution License (CC BY). The use, distribution or reproduction in other forums is permitted, provided the original author(s) and the copyright owner(s) are credited and that the original publication in this journal is cited, in accordance with accepted academic practice. No use, distribution or reproduction is permitted which does not comply with these terms. 